\title{
Futebol brasileiro: deleite estético e paixão intelectual
}

\author{
Brazilian Football: aesthetic delight and intellectual passion
}

\section{Alexandre Fernandez Vaz*}

\footnotetext{
Professor titular da Universidade Federal de Santa Catarina (UFSC, Brasil), no Programa de Pós-graduação Interdisciplinar em Ciências Humanas. Lidera o Núcleo de Estudos e Pesquisas Educação e Sociedade Contemporânea. Pesquisador do Conselho Nacional de Desenvolvimento Científico e Tecnológico (CNPq, Brasil). Doutor pela Universidade de Hannover, Alemanha.

$\varangle$-alexfvaz@uol.com.br http://orcid.org/0000-00034194-3876
}

RECIBID O: 28.8.2021 ACEPTADO: 26.10.2021

\section{Resumo}

Se o futebol é parte da cultura do Ocidente, e não só dele, é certo que se desenvolve com particularidades em cada contexto histórico e social. Fazem parte desse movimento as interpretações formuladas não apenas sobre ele, mas, a partir dele, sobre a sociedade em que se enraíza. No caso do Brasil, isso se coloca, entre outros aspectos, nas disputas em torno do que demarcaria certa autenticidade nacional. 0 futebol-arte convive com interpretações que veem no jogo um momento mais minimalista, técnico, mas nem por isso desprovido de expressividade estética, a qual se transforma, eventualmente, em deleite intelectual. 0 ensaio argumenta a favor de uma crítica cultural que considere a dialética do futebol como expressão modernizadora de um país periférico, ao passo que observa suas possibilidades expressivas, mas com algum distanciamento que autorize um comentário não apenas laudatório. 0 futebol pode ter expressão estética e dele se extrai material para a arte: literatura, cinema, pintura, teatro etc. Por outro lado, a crítica social não pode desprezar a materialidade do que acontece no interior do campo, tampouco alhear-se do que a compõe em seu enraizamento social: classe, etnia, gênero, geração e outros dispositivos que compõem a obra esportiva em sua expressividade.

Palavras-chave: esporte, Brasil, cultura 


\section{Albstract}

While football is part of Western culture, and not just of it, this sport develops with particularities according to each historical and social context. Part of this phenomenon are the interpretations formulated not only about it, but based on it, about the society in which it takes root. In the case of Brazil, this arises, among other aspects, in disputes over which features demarcate a certain national authenticity. Football-art coexists with interpretations that see in the game some minimalism in a technical moment, not without aesthetic expressiveness. This eventually turns into intellectual delight. This essay defends a cultural critique that considers the football dialectic as a modernizing movement of a peripheral country, while observing its expressive possibilities, but with some detachment that authorizes a comment which is not just laudatory. Football can have aesthetic expression and be material for art: literature, cinema, painting, theater etc. On the other hand, social criticism cannot despise the materiality of what happens inside the field, nor can it ignore what makes it up in its social roots: class, ethnicity, gender, generation and other devices which make up the work-of-sports in its expressiveness.

Keywords: sport, Brazil, culture

\section{Introdução: futtebol como narrativas sobre a nação ${ }^{1}$}

Em 27 de outubro de 2004 o Brasil assistiu à morte de um jogador de futebol em pleno exercício de sua profissão. Jogavam São Paulo Futebol Clube e Esporte Clube São Caetano, pela Série A do Campeonato Brasileiro. A partida, realizada Estádio Cícero Pompeu de Toledo, o Morumbi, casa do primeiro clube citado, já avançava pelo segundo tempo e repentinamente o zagueiro do time visitante caiu sobre o gramado. Soube-se depois que ele fora acometido por uma parada cardiorrespiratória e que, ao deixar o campo em uma ambulância rumo ao hospital, já se encontrava sem vida. Era conhecido

1 Uma versão bastante reduzida deste texto, e com diferenças importantes, foi publicada há dez anos sob o título de Soccer, Improvisation, Clichés: Brazilianness in Dispute (Vaz, 2011). Algumas de suas ideias foram antes apresentadas em duas ocasiões: a primeira em uma conferência em evento promovido pelos Serviço Alemão de Intercâmbio Acadêmico (DAAD) intitulado Futebol - História, negócios e paixão, em março de 2006; a segunda em mesa promovida pela Associação Brasileira de Antropologia durante a

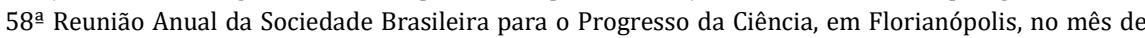
julho do mesmo ano. Agradeço a Danielle Torri a leitura e os comentários, sem responsabilidade. 0 trabalho - que compôs minha tese para Professor Titular, defendida na UFSC em 18.02.2021, sob o título de Esboços para uma Teoria Crítica do Presente: cultura, política, educação, é resultado parcial do Programa de Pesquisas Teoria Crítica, Racionalidades e Educação, que conta com apoio do CNPq, na forma de uma bolsa de produtividade (Proc. 310115/2017-5) e de um auxílio pesquisa (Proc. 423773/2018-6). 
como Serginho, confirmando essa estranha vocação brasileira para os diminutivos, em especial, como destaca Francisco Bosco (2007), no futebol.

0 choque foi grande no universo do esporte, mas também fora dele, já que o futebol não raro representa, no imaginário popular, fantasia e promessa de alegria, mesmo que momentânea, o que geralmente acontece em chave escapista ou mesmo em versão romântica. Tal sentimento parece ter sido o disparador de um curioso comentário de José Geraldo Couto (2004), crítico de cinema que à época mantinha uma coluna sobre futebol$^{2}$ no jornal Folha de São Paulo. Ele lembrou uma sentença emblemática e tornada polêmica do filósofo alemão Theodor W. Adorno. A assertiva, sobre a qual já se disse que foi uma das que mais causou mal-entendidos entre tantas e tantas de seu autor (Claussen, 1995), diz que "escrever um poema após Auschwitz é um ato bárbaro [...]". Como muitos, Couto não pronunciou o restante dela, que diz o seguinte: "e isso corrói até mesmo o conhecimento de por que hoje se tornou impossível escrever poemas" (Adorno, 1998, p. 26). Couto, aliás, diz - e o faz sem considerar a segunda parte da frase discordar de Adorno, afirmando que é preciso ter poesia e buscar beleza mesmo depois da expressão máxima do mal.

A sentença de Adorno é uma reelaboração de outra, de um de seus mestres, Walter Benjamin, de quem foi amigo e cuja obra mereceu por parte dele, como acontece com os grandes empreendimentos do espírito, admiração e crítica. Ela é conhecida e compõe a tese oito de Sobre o conceito da história: "Não há documento de cultura que não seja também documento de barbárie. E, do mesmo modo que ele não pode libertar-se da barbárie, assim também não o pode o processo histórico em que ele transitou de um para o outro" (Benjamin, 2016, p. 13), antecipando o que seria chamado de dialética do esclarecimento, o que se coloca na programática benjaminiana, e também depois na crítica cultural adorniana, é o imperativo de não esquecer, em especial de que a arte não oculte o sofrimento necessário para que a cultura e a civilização existam como tais. Ao reconhecer-se nesse lugar, a arte não pode, então, ela mesma, deixar de refletir sem horror sobre si.

Um dos grandes intelectuais do século vinte, Adorno, ao contrário de Couto ${ }^{3}$, jamais pôde ver beleza no futebol, assim como pouco ou nada em qualquer outro esporte, salvando-se, aqui e ali em sua obra, a prática, que teria o potencial da experiência em

2 Além de um bom número de colunas sobre o tema, Couto (2009) escreveu um livro pequeno e útil a respeito dessa expressão cultural com tanta força no Brasil, na série Folha Explica, sob o título de Futebol brasileiro hoje.

3 Adorno escreveu vários comentários sobre o esporte ao longo de seus trabalhos. Pretendia, inclusive, elaborar uma reflexão mais densa, em ensaio especialmente destinado a isso, sobre o caráter do esporte na sociedade contemporânea, um projeto que, como muitos, foi abortado por sua prematura morte em 1969. A relação de Adorno com o esporte foi pesquisada por Morgan (1994), Vaz (2004), entre outros, e tematizada de forma ficcional por Bero Rigauer (2000). 
relação ao corpo do outro (e ao próprio, se poderia acrescentar), mas jamais sua dimensão de espetáculo, entendido por ele como uma espécie de voyeurismo sadomasoquista. O grande dialético escreveu instigantes parágrafos sobre esporte, frases que, com o habitual desconcerto que causam no leitor, fazem-no pensar, se houver coragem para tal, além de serem, por si mesmas, precisas. Ele, no entanto, jamais criticou de forma imanente as práticas esportivas, mantendo-se como um observador externo, ainda que atento e sensível, ao fenômeno.

Vale para o futebol o que apontou Martín Kohan em entrevista a Idelber Avelar (2006, s.p.) sobre as tensões entre cultura popular e cultura erudita, segundo Adorno:

A antinomia entre "alta cultura" e "cultura de massas" é um tanto redutora, e também esquemática, e também simples em demasia, e também rígida demais; e, no entanto, no meu ponto de vista, apesar do já dito, ela é substancialmente verdadeira. Acontece com os enfoques de Theodor Adorno: inclusive ali onde exagera, ali onde evidentemente não tem razão, diz, entretanto, uma verdade: tem razão. É claro que é um problema para a teoria cultural ver como se continua pensando depois de que alguém formulou uma crítica tão fechada e tão taxativa, e, no entanto, tão verdadeira.

A breve crítica de Couto (2004) conjuga dois temas que a princípio parecem mutuamente excludentes, mas que convidam, por sua pertinência e importância, e porque a tensão entre eles pode ajudar a pensar sobre o tempo que nos coube viver, ao exercício interpretativo. 0 comentário faz encontrar o futebol com a crítica cultural. Tomar o futebol como expressão da cultura e fora da chave que o coloca como reprodutor da ordem dominadora da sociedade administrada, demarcada pelo fanatismo e pelas manifestações de irracionalidade de torcedores, bem como pela disputa violenta no campo, é o que faz o autor recorrendo ao ensaio de Adorno (1998) cujo título é, precisamente, Crítica cultural e sociedade. Reafirma, nesse movimento que é quase um curto-circuito, o impulso de intelectuais e críticos da cultura que se ocupam ou se ocuparam de esportes, geralmente com boa dose de deleite estético e de paixão por eles e, eventualmente, de paixão intelectual.

A posição do crítico pende para uma das duas trincheiras do debate, ambas sendo menos modelos interpretativos e mais pontos de partida que de antemão podem condicionar o resultado da análise, qualquer que seja ela. Refiro-me à perspectiva segundo a qual o futebol é o ópio do povo, de um lado, e que ele é um grande momento da identidade nacional, de outro. 0 principal representante da primeira corrente talvez seja o argentino Juan José Sebrelli, o da segunda, o brasileiro Roberto DaMatta. ${ }^{4}$ Tendendo a

$4 \quad 0$ trabalho mais emblemático que sucede ao de DaMatta, mantendo-lhe as grandes linhas e encontrando originalidade, é o de Simoni Guedes. Eduardo Archetti e Pablo Alabarces, na Argentina, sustentam a 
nele encontrar uma poética, situa-se José Miguel Wisnik (2008) que, apoiado em Hans Ulrich Gumbrecht (2007), mas sem deixar de ser original, encontra a fórmula no farmacum, ou seja, na relação entre veneno e remédio, conforme a dose do princípio ativo.

Nesse contexto se coloca este texto, que procura apresentar e interpretar uma narrativa corrente sobre futebol brasileiro, aquela que o considera arte, mas na forma do improviso e quase sob a chave do belo natural, opondo-lhe uma outra, que o vê, igualmente artisticamente, mas como expressão minimalista, valorizando a precisão e certo rigor formal. Isso é feito nos termos de uma visita a discursos intelectuais e estéticos sobre o futebol.

A presença de intelectuais escrevendo até mesmo de forma regular sobre o futebol é algo não propriamente novo, mas com marcante singularidade. Tomar o futebol como tema legítimo da crítica cultural, à altura da literatura, do teatro, da música, das artes plásticas, do cinema, é tarefa arriscada, mas vale a perspectiva segundo a qual tudo pode ser documento de análise para uma investigação, como ensinam os historiadores, assim como o exemplo de Adorno (1992), que em suas Minima Moralia vai ao fundo das situações mais banais e corriqueiras do dia a dia para dali extrair toda uma ordem econômico-social que, além das relações estruturais, produz seus poderosos dispositivos de subjetivação. Como síntese dessas duas inspirações, menciono a introdução de Mitos, emblemas, sinais, em que Carlo Ginzburg (1989) lembra que um dos livros mais importantes de sua formação é exatamente o de Adorno, de fato, um exemplo de micrologia do que ele chamou de vida estragada.

Que o futebol possa expressar sem necessariamente comunicar, ou seja, ser admirado como empreendimento estético que produz sentido a partir de forma - como obra de arte -, não me parece discussão vencida, apesar dos esforços importantes de trabalhos como os de Wolfgang Welsch (1999), Gumbrecht (2007) e Wisnik (2008). 0 que se pode dizer é que há uma dimensão estética no esporte que pode, talvez, ser pensada como obra esportiva (Gonçalves e Vaz, 2017). A mirada estética sobre o esporte esbarra, no entanto, no limite de ser ele prática competitiva, subordinada ao interesse pela vitória. Com tal perspectiva prevalecendo, a expressividade esportiva não teria, como na artística, critérios próprios, ainda que socialmente mediados, para sua sabermos de sua força; ao contrário, manter-se-ia a redução a um interesse que rege sua prática, que é o da conquista da competição.

\footnotetext{
mesma posição geral, mas com diferenças que não devem ser desprezadas. Quanto a Sebrelli, que é bom crítico da cultura e da política, sua posição é pouco dialética, aproximando-se, por exemplo, de Gerhard Vinnai, cujo livro sobre futebol, publicado por primeira vez na Alemanha, Fútbol e ideología, teve várias edições no México e, com isso, alguma influência na América Latina. Apesar dos aspectos datados, os trabalhos de Bero Rigauer e Jean-Marie Brohm, dois dos mais importantes para a fundação de uma teoria crítica do esporte, nos anos 1960 e 1970, são muito mais refinados do que os de Sebrelli e de Vinnai.
} 
Por outro lado, o futebol está pouco presente, como tema central, na literatura, no cinema, nas artes plásticas e na dramaturgia, ainda que exceções sejam notáveis. Entre outros, citam-se o inventor desse esporte como tragédia, Nelson Rodrigues, e ainda uns tantos, como Carlos Drummond de Andrade (Quando é dia de futebol, 2014), Sérgio Rodrigues (O drible, 2013), Sérgio Sant'anna (Páginas sem glória, 2012), na literatura; Eryk Rocha (Campo de jogo, 2014) e Walter Salles e Daniela Thomas, no cinema (Linha de passe, 2008); Rubem Gerchman na pintura (a exposição Estética do futebol e outras imagens, 2013); Dias Gomes no teatro (Os campeões do mundo, 1980).

É claro que há ampla pesquisa sobre esportes nas Humanidades, da Literatura à Antropologia, da Filosofia à Sociologia, da História à Psicologia, mas estes são lugares de quem se ocupa do tema academicamente. Com alguma frequência são pesquisadores também apaixonados por seus objetos, o que, como sabemos, traz vantagens e desvantagens (algo que costuma acontecer, aliás, com qualquer lugar de onde de faça o exercício analítico). Já temos um bom fluxo de trabalhos sobre esporte nas diferentes áreas do conhecimento ou mesmo sob abordagem interdisciplinar, com alcances e profundidade diversa, ainda que não seja ele um dos temas mais nobres da investigação universitária. Mas não é esse o rastro aqui procurado, se não aquelas construções que se dirigem ao futebol procurando-lhe a expressão estética, produzindo-a, reconhecendo-a, escrevendo-a.

\section{Escrever sobre o jogo}

Há também cronistas esportivos, muitos deles com uma prosa fluida e concisa e que se debruçam sobre o futebol para além da conversa reiterativa das mesas-redondas de domingo ou segunda-feira, mostrando desse esporte uma beleza que só enriquece o jogo e seu entorno. Nelson Rodrigues certamente foi o maior de todos, mas João Saldanha, Mário Filho, Sandro Moreyra e Armando Nogueira são exemplos dessa capacidade de ver no futebol algo que mereça ser assunto da prosa jornalística ou da crônica de costumes. Muitos deles vieram do rádio e fazem da redação um exercício de lírica futebolística. 0 esporte, e o futebol em especial, não seriam o que são hoje sem a imprensa, que ajudou a educar os leitores-torcedores para a fruição e o consumo do espetáculo dos estádios. Se é evidente que o jornalismo ajudou a criar o campo esportivo - Hugo Lovisolo já chamou a atenção para o fato de a principal revista esportiva argentina ter como título El Gráfico - é também porque contamos com cronistas de grande talento e que viram no futebol um espetáculo de dramaturgia, uma tragédia que seria capaz de expressar nossas grandezas, nossos fracassos, um pouco para além de nossa habitual mediocridade, os quais isso com graça e gosto e talvez não tenhamos hoje autores à altura do que eles representaram. 
Quem também escreve regularmente sobre o tema para importantes jornais são ex-jogadores profissionais, alguns deles com brilho, como o tricampeão mundial pela seleção brasileira no México, Eduardo Gonçalves de Andrade, o Tostão, e Jorge Valdano, atacante do selecionado argentino campeão do Mundial de 1986. Além disso, há outros nem tão hábeis com as palavras, como os futebolistas alemães Lothar Matthäus e (o excepcional jogador) Franz Beckenbauer, colunistas do tabloide popular Bild.

Há ainda os intelectuais (e aqui incluo, com alto grau de liberdade, artistas) que dedicam sua atenção a temas e materiais diversos e que, ao debruçarem-se sobre o futebol, lançam-se com a fleuma do torcedor, mas também com a competência que seu oficio de origem lhes empresta. Alguns deles de fato conhecem bem a dinâmica do jogo entre as quatro linhas, costumando fazer comentários apropriados que apenas os envolvidos com a cultura futebolística seriam capazes de elaborar. Não raro é a memória afetiva desses articulistas que emerge com precisão e clareza de detalhes, até mesmo técnicos e táticos, às vezes na forma de ficção.

Não me é alheio o fato de que muitos que desse grupo fazem parte são também professores e pesquisadores universitários ou com grande importância no mundo acadêmico. Antonio Negri é um exemplo, com textos e entrevistas meticulosas sobre o calcio, em especial sobre o AC Milan, seu time do coração. ${ }^{5}$ São também muito bonitos os textos de cronistas, contistas, professores de filosofia e musicólogos brasileiros sobre o futebol. Além de narrativas tristes, às vezes trágicas e dramáticas, dá prazer ler um fragmento sobre um gol de Romário como este escrito por José Miguel Wisnik (2002, s.p.): "um raio de saci-pererê em céu azul, de uma objetividade atordoante". São escritos que fazem emergir a memória que envolve a infância, as rememorações do corpo em movimento em coreografias não treinadas em relação à bola e outros garotos; relatos inspirados na paixão da torcida, narrativas que identificam uma beleza no gesto corporal, na definição do momento que dá o golpe definitivo e acaba em gol. 0 escritor Marçal Aquino (2002, s.p.) traz mais um belo exemplo:

Naquela tarde, o clássico teve pouco brilho. Jogo truncado, de marcação cerrada, os zagueiros levaram vantagem. Dois times, e dois técnicos, com medo de perder. Até que a mágica aconteceu. 0 jogo estava no fim quando ele recebeu a bola, de costas para seu marcador, e, com um giro de corpo, livrou-se dele. Um arranque para dentro da área e encontrou o ângulo para o chute de pé esquerdo. Que saiu forte, indefensável. Na comemoração, parou na beira do gramado, agitando os braços levantados. Até ser engolfado pelos abraços dos companheiros. Ao voltar para 
o meio do campo, parecia envolvido por um halo de luz. Era um deus naquele momento. Um deus reverenciado com grande ruído por fiéis, que gritavam nas arquibancadas.

Os textos de alguns intelectuais brasileiros nos mostram como se referem ao fenômeno futebolístico e de que forma o localizam - e se o fazem - no território das interpretações e das narrativas sobre o país, além de como respondem, com suas investidas sobre o futebol a perguntas sobre o Brasil. Dito de outra forma, coloca-se, uma vez mais, a disputa pelas narrativas não apenas a respeito do futebol, mas, por meio dele, sobre o Brasil.

Como já afirmei, muitos de nossos intelectuais escrevem seus textos a partir da memória afetiva de espetáculos futebolísticos. Eles são frequentemente vividos nos estádios, mas tantas outras vezes são reminiscências oriundas da audição de partidas que, narradas pelo rádio, tornam-se verdadeiras batalhas em que jogadores, como guerreiros, se tornam heróis. Na transmissão via rádio, um chute que passa a vários metros da meta torna-se um quase-gol. É assim que se reforça, em certa crônica futebolística, a louvação dos feitos de brasileiros em países vizinhos ou além-mar. Como exemplo, diz tal mitologia que Pelé, ainda criança, teria visto seu pai, o ex-jogador Dondinho, cuja carreira fora abreviada por grave contusão, chorar junto ao rádio a derrota da seleção brasileira frente à do Uruguai, em 1950. Frente a tal cena, aquele que se tornaria o melhor dos melhores jogadores da história do futebol teria prometido a ele a vitória em uma Copa do Mundo, promessa cumprida aos dezessete anos, em 1958, a qual teve, no entanto, seu segundo ato no ano seguinte, em Montevidéu, em disputa do campeonato sul-americano: em uma noite de Quinta-feira da Paixão de Cristo, com os adversários do Maracanazo de nove anos antes se criou uma verdadeira batalha campal, configurando a vingança, em nome do pai, de Pelé. Deste e de tantos outros embates esportivos, sabemos pelas narrações radiofônicas assim como pelos relatos jornalísticos literários que amiúde apresentam valor literário.

Essa memória afetiva é, para os brasileiros, a dos atacantes, com preferência para os fazedores de gols: Leônidas, Friedenreich, Romário, Ronaldo, Zico, obviamente Pelé e Garrincha; em menor medida, apesar do grande talento, Reinaldo e Careca. Dadas as narrativas que circulam sobre ele, é improvável que Neymar venha a compor esse panteão. Ela alimenta aquelas duas direções interpretativas e estilísticas distintas que tomam o futebol como tema e alcançam a sociedade brasileira como um todo, mencionadas na introdução. Vamos a elas para saber de algumas de suas características e, no melhor dos casos, consequências. 


\section{Sobre a mitologia do futebol-arte}

Há uma tradição narrativa que entre nós fez e faz o elogio da mestiçagem, de uma utopia racial que seria democrática e redentora de nossas mazelas. Seu artífice mais dedicado foi Gilberto Freyre, sendo exemplares suas duas grandes obras, Casa grande e senzala e Sobrados e mucambos. Constantemente atualizado - e já há algum tempo muito criticado -, tal ideário encontra sua mais bem-acabada versão, possivelmente, em interpretações de Roberto Mangabeira Unger (2018). A crítica a Gilberto Freyre (2003) vem sendo feita de diferentes modos, destacando, de modo geral, o pouco peso atribuído à violência na mestiçagem, tanto pela submissão escravista de uma das três raças irmãs quanto pelo extermínio de outra. É fato que em Casa Grande e Senzala (Freyre, 2003), de qualquer forma um clássico de nosso pensamento social, há um elogio do erotismo que o homem branco teria desenvolvido em relação à mulher negra, com frequência ignorando a relação assimétrica e violenta entre ambos.

Esse ímpeto mestiço estaria presente também no futebol em suas peculiaridades nacionais. É de Freyre que deriva a hipótese da transferência de um tipo de gesto lúdico para o futebol, jogo que seria aparentado com a capoeira e, portanto, repleto de ginga, sintetizando uma representação do brasileiro em geral, algo que não passaria despercebido, tampouco, a um intelectual como Anatol Resonfeld (1993). Não por acaso, Freyre escreveu de forma vital sobre nossas vitórias e nossa maneira, segundo ele, dionisíaca de jogar, inaugurando o louvor do que viríamos depois a chamar de futebol-arte.

Na década de 1950, antes do triunfo na Suécia, Freyre não deixa dúvidas sobre a diferença entre o estilo brasileiro de jogar e seu correlato europeu, o nosso associado ao negro, à capoeiragem, virtude que teria resistido até mesmo às derrotas de 1950 e 1954 e que estaria vinculada "às reminiscências africanas, que estariam tornando [ao futebol] antes dionisíaco, isto é, expansivo, alegre, improvisador, 'baiano', [...] que apolíneo" (citado por Barreto, 2004, p. 236).

No prefácio do livro de Mario Filho, ${ }^{6}$ O negro no futebol brasileiro, Freyre (2003, p. 25) escolhe um zagueiro, Domingos da Guia, para um comentário, mas, antes, confirma, pela exceção, a regra da mitologia dos atacantes, que procura instituir discursivamente:

A capoeiragem e o samba, por exemplo, estão presentes de tal forma no estilo brasileiro de jogar futebol que de um jogador um tanto álgido como Domingos, admirável em seu modo de jogar, mas quase sem floreios - os floreios barrocos tão ao

Para o estudo da obra de Mário Filho, é importante mencionar o trabalho de Antônio Jorge Gonçalves Soares (1999), que a entende antes como expressão narrativa da construção heroica de jogadores negros no futebol nacional do que construção histórica do fenômeno do racismo entre nós. Soares desenvolve seus argumentos na comparação heurística entre as duas edições do livro. 
gosto do brasileiro - um crítico da argúcia de Mario Filho pode dizer que ele está para o nosso futebol assim como Machado de Assis para nossa literatura, isto é, na situação de uma espécie de inglês desgarrado entre tropicais. Em moderna linguagem sociológica, na situação de um apolíneo entre dionisíacos.

Logo depois, Freyre (2003) destaca que o domínio de si dos mestiços Domingos da Guia e Machado de Assis caracterizaria o caráter apolíneo que, no entanto, não impediria de fazer emergir, numa pesquisa mais profunda, os traços baianos (capoeiragem), cariocas (malandragem), ameríndios. Tanto o grande zagueiro quanto nosso maior escritor seriam ingleses desgarrados por aqui, claras exceções em um universo de atacantes mágicos no qual a literatura não tinha ainda uma tradição comparável às dos países europeus.

Dessa utopia compartilham intelectuais como Darcy Ribeiro (1996), segundo o qual talvez tenhamos sido derrotados nas semifinais dos Jogos Olímpicos de 1996 - adiando mais uma vez a chance do ouro, único triunfo futebolístico que nunca obtivéramos, conquistado pela primeira vez nas Olimpíadas de 2014, no Rio de Janeiro - porque tínhamos poucos negros no elenco da seleção. Perdemos, é bom lembrar, para o selecionado da Nigéria, cujo time era inteiramente formado por jogadores negros. Perguntava ele, então, em sua coluna em um jornal diário:

Não sei nada de futebol, só vejo as partidas das Copas e, agora, da Olimpíada. Mas o que vi não só me entristeceu, também me preocupou muito. Não sou racista, mas não está faltando negro no futebol brasileiro? Veja os negrões da Nigéria, não sabem jogar futebol, mas têm uma raça e uma alma que arrasaram os nossos moreninhos. (Ribeiro, 1996, p. 2)

Também é tributário desta tradição Roberto DaMatta, notável como acadêmico e durante muitos anos articulista semanal em grandes jornais brasileiros. 0 antropólogo analisou o futebol e foi o grande responsável pela legitimação desse esporte como tema de pesquisa no Brasil, com a organização, em 1982, do livro Universo do futebol, espécie de subproduto de seu livro-programa Carnavais, malandros e heróis, publicado três anos antes (DaMatta, 1979). Ao lado do carnaval, das paradas militares e das festas populares, o futebol seria uma maneira de entender o Brasil pelo avesso, ou seja, por um lado que não o das grandes análises políticas e econômicas. Para DaMatta, trata-se de entender o futebol como drama de justiça social. Seguindo o caráter originalmente liberal do esporte, o autor propõe que o futebol seria uma esfera democrática porque baseada em regras universais e conhecidas por todos, prática hierarquizada pelo mérito do desempenho individual e coletivo. Essa relação que DaMatta (1982) identifica entre o esporte e a democracia, o primeiro como uma experiência pedagógica para o segundo, poderia 
ser sustentável se ainda vivêssemos no século XIX, em que as práticas esportivas eram distintivas para seus praticantes, que a elas se dedicavam de forma puramente amadora, desinteressada, que vedava aos profissionais sua participação nos Jogos Olímpicos, evento que se inaugura em 1896. Isso era, ao menos, o que sustentavam no plano discursivo, mas então não teríamos democracia, já que não é de todos que estamos falando, mas dos nobres, burgueses de alta extração e alguns poucos privilegiados de camadas sociais mais baixas. 0 esporte não é isso, ao menos não mais, mas uma prática altamente competitiva que se baseia na igualdade formal de chances, contudo funciona exatamente pela desigualdade de condições que oferece.

DaMatta diz mais. ${ }^{7}$ Vem dele o estatuto acadêmico conferido à ambígua figura do malandro - em direção distinta daquela consagrada por Antônio Cândido (1970) - como marca da nossa sociedade e, dentro das quatro linhas em que acontece o drama, daquilo que seria nosso jeito de lidar com o indeterminado. Aqui prevaleceu, em detrimento dos países anglo-saxões e não por acaso, a versão soccer do futebol (DaMatta,1994), jogado com os pés e movido pelos quadris e, portanto, mais dado à imponderabilidade, à imprevisibilidade. Essa seria uma expressão de nossas diferenças para com os Estados Unidos da América, país em que ele lecionou por mais de uma década, cuja democracia representativa teria predileção pela exatidão do jogo com as mãos (DaMatta, 1994). Trata-se de uma especulação que só pode ganhar corpo se houver base empírica para ela, o que o autor não apresenta. Além do mais, não é de todo verdadeiro que o futebol jamais fora popular nos Estados Unidos da América, como mostra Detlev Claussen (2014). Quase que retomando, mas pelo avesso, a assertiva de Friedrich Nietzsche que os impulsos do baixo ventre impedem que o ser humano se arvore a ser deus, DaMatta assevera que:

A ênfase na mão que simboliza o que está acima da cintura (esse equador simbólico do mundo ocidental) e tem ligação com a razão a humanização e com a civilidade, acentua uma índole social preocupada com o controle e a disciplina. [...] E nada mais sintomático do que um esporte praticado com os pés para significar uma sociedade muito mais preocupada com a terra e com o conflito entre planejamento, destino e liberdade individual. Um futebol que mistura corpos põe o território em plano secundário e multiplica as possibilidades de erro. (DaMatta, 2005, pp. 284-285)

A certeza do poder heurístico do futebol para a compreensão da sociedade brasileira pode levar a simplificações, como atribuir uma correspondência entre a conquista

7 As questões sobre DaMatta mereceram minha atenção em vários trabalhos, como, por exemplo, Vaz (2021). 
da Copa do Mundo de 1994 pela seleção brasileira e a vitória eleitoral de Fernando Henrique Cardoso, alavancada pela implementação de um plano econômico de combate à inflação. Seriam ambos eventos marcadores de um novo tempo (DaMatta, 1994), com mais racionalidade, a qual seria encontrada no futebol mais tático e escasso em improvisação apresentado pelo time nacional nos Estados Unidos da América. À tentação de colocar as coisas num mesmo plano, sem a devida mediação, tampouco resistiu Everardo Rocha (1996), que afirmou que o time brasileiro provara ser possível vencer como "alemães", o que seria demonstrado também pelo sucesso nacional da Fórmula 1, modalidade em que a tecnologia do carro e o cálculo preciso dos engenheiros se associam à capacidade do piloto.

Gostaria de citar rapidamente mais uma expressão dessa leitura hegemônica do futebol brasileiro e de seu potencial heurístico para a compreensão da sociedade. Tratase do belo documentário cinemanovista Garrincha, alegria do povo, de Joaquim Pedro de Andrade (1963). 0 filme começa com uma ode à "natureza pura" do futebol brasileiro, supostamente nascido nas praias, no campinho em que nossos craques emergem e se desenvolvem com "liberdade". Depois, temos uma sequência sem locução na qual são mostrados em ordem vários dribles e outras jogadas do jogador Garrincha - e suas pernas tortas -, a violência dos adversários que impedem que ele avance na direção do gol e, logo após, a impossibilidade de barrá-lo, a brutalidade dos adversários sendo insuficiente para parar o craque que aparece marcando muitos gols. Alguns minutos depois, o filme inscreve Garrincha naquela tradição mitológica que este texto aborda, ao mostrá-lo no pequeno município de Pau Grande, onde possuía casa, mulher e sete filhas, confraternizando com aqueles classificados como seus "verdadeiros amigos", com os quais joga futebol em campo de terra algo enlameada.

A seguir, a narrativa fílmica diz que nada pode detê-lo em sua espontânea genialidade, nada é capaz de adestrá-lo: nem os patrões da indústria têxtil em que trabalhara antes de profissionalizar-se no futebol, nem os treinadores - ele desobedecera Aimoré Moreira, na Copa de 1962, ao não manter-se na ponta-direita, ocupando todas as partes do campo -, tampouco os preparadores físicos, tenazes na tentativa de cumprir o dever de deixar o grande jogador dentro dos limites de peso ideais para a performance esportiva. Há mesmo um desafio à própria razão, expresso pelo depoimento de um diretor do Botafogo de Futebol de Regatas - clube em que Garrincha jogou a maior parte de sua carreira profissional e pelo qual conquistou muitos títulos - no qual o médico traumatologista assevera que ele, se não fosse conhecida sua habilidade, não seria aceito, com aquela deformação corporal, em um clube profissional de futebol. Mas há o contraponto a isso, aquele que prevalece no filme: o da benzedeira, o da superstição, ${ }^{8}$ que - é quase

8 Talvez não haja outro território em nossa sociedade globalizada que tão bem conjugue toda sorte de crendices, de um lado, e a ciência em alto grau (da performance atlética, neste caso) de outro. Não é incomum em grandes clubes do futebol brasileiro que se faça conviver um laboratório de fisiologia do 
sugerido - faz vencer a Copa do Mundo de Futebol de 1962, momento de glória suprema da carreira de Garrincha. Confome acompanhamos a narrativa do filme, compreendemos que ele teria feito esquecer Pelé, cuja participação se limitaria a menos de dois jogos completos devido a uma grave lesão, marcando gol como Didi (de "folha seca"), outro de cabeça, e ainda um tento mais que improvável com a perna esquerda. Vemos ademais o "povo" na tela do cinema, que com seu herói se identifica, nas ruas ou arquibancadas, no exercício de sua diversão como disciplina (Pereira e Vaz, 2012).

Todo esse movimento, tomado aqui em suas características comuns e não em suas rachaduras e divisões internas, posiciona-se na disputa pelas interpretações e narrativas sobre a sociedade brasileira. Talvez seja o caso de lembrar, antes de passar à última parte do texto, que há pelo menos outra possiblidade de ver a problemática, sugerindo que nem sempre o que faz pensar é necessariamente bom para explicar.

\section{Outra leitura, quem sabe, outra tradição}

Há outro veio, talvez não prevalecente no nosso imaginário, ou pelo menos algo oculto, que se refere à memória que rivaliza com o mito do futebol-arte, valorizando a linha reta, a jogada minimalista, a técnica como economia e domínio sobre a natureza e não a expressão espontânea desta última.

Nesse quadro aparece, por exemplo, o texto do professor de Filosofia Bento Prado Júnior sobre o fantástico gol de Ronaldinho no jogo em que o selecionado brasileiro enfrentou e venceu o inglês na Copa de 2002. Arguindo um tema clássico da Estética, o da superioridade do belo como artefato humano sobre a beleza natural a ser contemplada, escreve o seguinte:

Era preciso que o regime dos ventos, que a natureza anônima e irresponsável, que tudo que escapava à intenção original, que o Kairos (como os gregos denominavam o puro acaso ou a boa oportunidade), que tudo isso viesse paradoxalmente como que corrigir a intenção original, para depurá-la de suas imperfeições, fazendo-a coincidir, finalmente, consigo mesma.

Como se, por milagre, num instante, a natureza se tornasse cúmplice, uma espécie de pista de esqui muito bem-feita, para permitir ao atleta atingir seu fim sem nenhum atrito.

esforço dos mais avançados e, logo ali, um Pai-de-santo. Por via das dúvidas, melhor garantir um amplo arco de alianças, não? Faz coro com essa construção o filme ficcional Boleiros, de Ugo Giorgetti (1998), em que, em um dos episódios, um Pai de Santo cura o joelho lesionado de um importante jogador do Sport Club Corinthians Paulista. 
Uma espécie de "perfeição" que os homens acreditam encontrar, por exemplo, nos diamantes: esse bruto produto natural que parece exprimir a mais sofisticada inteligência geométrica.

Mas esse diamante não nos foi dado pela natureza ou pelo regime dos ventos. Ele foi produzido intencionalmente pelo Ronaldinho, o gaúcho, que quis botar a bola no ângulo inacessível ao guarda-metas da Inglaterra.

E ele conseguiu.

Que felicidade! (Prado Júnior, 2002, p. d5)

Como já assinalei, há intelectuais que se dedicam ao futebol com conhecimento de causa, conhecedores que são da cultura futebolística, inclusive em seus aspectos técnicos e táticos. Entre eles, e com destaque, está o crítico teatral Décio de Almeida Prado (1997), cuja prosa deve muito à prodigiosa memória de quem frequentou o Estádio do Pacaembu e que relata detalhes sobre o jogo que só o estilo e a concisão ensaísticos são capazes de oferecer. De seu texto emergem personagens de um tempo com poucas imagens televisivas e mesmo fotográficas, se compararmos com os dias de hoje. Leônidas da Silva e Arthur Fridenreich - a memória e o elogio privilegiam, como já destaquei, os atacantes - seriam expressão da linha reta, do gesto por vezes minimalista e do compasso certeiro na grande área. Nos termos aqui postos, o herdeiro privilegiado seria Romário, cujo gesto foi celebrado por Wisnik (2002) algumas páginas antes.

Referindo-se a Leônidas, o crítico paulista escreve, no início dos anos 1960, o seguinte:

Leônidas era a própria encarnação da habilidade, e a habilidade, no espírito brasileiro, sempre aparece ligada à ideia de individualismo. Explica-se, desse modo, creio eu, a imagem popular - a que Mario Filho deu acolhida, com grande imaginação, no seu livro 0 negro no futebol brasileiro - de um Leônidas malabarista até a excentricidade, plantando bananeiras no campo, divertindo-se com a bola como se fosse um brinquedo. Não sei se o Leônidas carioca era assim: pouco posso testemunhar sobre o Leônidas juvenil ou mesmo sobre o artilheiro do Campeonato do Mundo de 1938, que maravilhou os europeus, deixando uma impressão que perdura intacta até hoje. 0 que garanto é que o Leônidas amadurecido que conheci em São Paulo, domingo após domingo, durante tantos anos, punha todo o seu virtuosismo a serviço do time - e se não o pusesse, não seria um grande jogador. Nos momentos de relativa folga, fazia sem dúvida as suas viagens, os seus passes de mágica sobre a bola, talvez para mimar a torcida, talvez para impressionar o adversário, talvez por um resto de molecagem, pelo prazer de viver. Mas que ninguém se enganasse com tais fantasias, aliás, de pouco efeito prático (Prado, 1997, p. 191). 
É forte o contraste interpretativo com a tradição de Freyre (2003). Se o discurso de Décio de Almeida Prado (1997) não contraria inteiramente o que nos ensina a interpretação hegemônica de pensar o futebol brasileiro, oferece, pelo menos, uma narrativa concorrente à mitologia do futebol-arte, da malandragem, do elogio ao quadril. Com isso, sugere outra mirada estética sobre o fenômeno, menos divertida - e menos infantil - e mais comprometida com a forma. Sem perder o sentido do esporte, tem-se a busca da vitória, e que assinala a exatidão, a economia do gesto, como se os jogadores fossem atores que descobriram a essencialidade do gesto, sua mínima ação para alcançar o máximo de expressividade.

\section{Uma nota final}

As narrativas sobre a identidade nacional vinculadas, reforçadas e representadas pelo futebol podem ser pensadas como uma espécie de expressão inconsciente de um tempo e não como discursos estáticos. Precisam assumir, então, seu caráter de invenção das tradições, conforme a proposição de Eric Hobsbawm (1983) para esta expressão, assim como o caráter imanente que os discursos devem possuir, guardando sua contemporaneidade em relação à dinâmica do futebol em seus desdobramentos sociais. 0 que vale para o tempo vale igualmente para o espaço. Os discursos sobre identidades contêm sempre o risco de solapar diferenças e singularidades, buscando um essencialismo que pode estar no imaginário - e por isso deve ser considerado -, mas que dificilmente encontrará radicação empírica. O Brasil não é apenas o Rio de Janeiro, tampouco São Paulo, apesar da inquestionável importância dessas duas metrópoles como produtoras e disseminadoras culturais. 0 futebol, portanto, não é jogado apenas nesses lugares.

Podemos sair dos clichês e tentar esboçar modelos de interpretação. Um bom começo é a crítica à perenidade da categoria malandragem para a compreensão da sociedade brasileira. Elogio da astúcia e da capacidade de lidar com adversidades pelo desvio de forças que não podem ser encaradas, ela perde força ao associar-se à indeterminação e ao improviso. 0 elogio da criatividade não é a defesa de uma improvisação que fosse natural, mas daquela que pode emergir a partir de repertório técnico amplo e domínio corporal apurado; na tradição, é o encontro entre mimesis e techné. Ademais, como sugere Rocha (2006), a dinâmica da sociedade brasileira ultrapassou as possibilidades analíticas do malandro ao instituir uma nova dialética, a da marginalidade. Sobreviveria o malandro no futebol?

Ressentimo-nos de uma crítica cultural que possa fazer a crítica radical de nosso futebol, o que não significa repudiá-lo, o que seria cair no velho chavão do futebol como ópio do povo. Talvez os filmes de João Moreira Salles e Arthur Fontes (1998) - os três documentários que compõem Futebol - e o de Ugo Giorgetti - Boleiros -, além da prosa 
de Marçal Aquino (2002), encontrem uma forma artística, um equilíbrio na leitura que guarda a paixão pelo objeto e algum distanciamento que autorize um comentário não apenas laudatório.

Temos aí, portanto, a problemática de que o futebol pode ter expressão estética e que dele pode-se extrair material para a produção de uma obra de arte: literatura, cinema, pintura, teatro etc. Por outro lado, a crítica social, se não pode deixar de ater-se com a materialidade do que passa no interior das quatro linhas do campo, tampouco pode alhear-se do que a demarca em seu enraizamento social, quando classe, etnia, gênero, geração e outros dispositivos compõem a obra esportiva em sua expressividade.

Volto ao texto de Adorno que citei no início, aquele mencionado por Couto por ocasião do episódio que pôs fim à vida do jogador Serginho. Não se trata de uma "proibição ao futebol", tanto quanto não era o caso, quando Adorno publicou o polêmico ensaio, de uma proibição da lírica. A questão é: que nossa identificação com ele, com seu momento de jogo e de espontaneidade, que faz, sim, tremer no fascínio estético, não nos faça esquecer o elemento de reificação e tudo que ele anuncia.

Pier Paolo Pasolini (2005) escreveu que o futebol brasileiro era escrito em poesia, assim como o italiano em prosa, sem que designasse uma relação hierárquica entre ambos. Deixemos que o jogo nos leve à mimese pela fruição proporcionada pela beleza da prosa e da poesia de sua efetivação (Wirklichkeit), assim como nas palavras e nas imagens de nossos intelectuais e artistas. Esse jogo está no esporte assim como na arte: Schauspiel - teatro - assistir ao jogo, à dramatização. Talvez, além do prazer que pode nos trazer a fruição, tanto quanto ou mais que a torcida, aprendamos com o futebol algo sobre o que temos sido, mesmo em facetas que os mestres não foram capazes de nos ensinar.

\section{Referências}

Adorno, T. W. (1992). Minima moralia: Reflexões a partir da vida danificada. São Paulo: Ática.

Adorno, T. W. (1998). Prismas: Crítica cultural e sociedade. São Paulo: Ática.

Andrade, J. P. (Director). (1963). Garrincha: Alegria do povo. [Filme]. Brasil.

Aquino, M. (2002, 5 de Junho). Um guerreiro sai de cena. Folha de São Paulo. Recuperado de https://www1.folha.uol.com.br/fsp/esporte/fk0506200239.htm.

Avelar, I. (2006). Entrevista com Martín Kohan. Recuperado de http://idelberavelar.com/index.php/2006/06/09/entrevista-com-martin-kohan/.

Barreto, T. V. (2004). Gilberto Freyre e o futebol-arte. Revista USP, 62, 233-238.

Benjamin, W. (2016). O anjo da história. (2ª ed.). Belo Horizonte: Autêntica.

Bosco, F. (2007). Banalogias. São Paulo: Objetiva. 
Cândido, A. (1970). Dialética da malandragem. Revista do Instituto de Estudos Brasileiros da USP, (8), 67-89.

Claussen, D. (1995). Nach Auschwitz kein Gedicht? Em G. Schweppenhäuser, M. Wischke (orgs.), Impuls und negativität (pp. 44-51). Hamburgo: Argument.

Claussen, D. (2014). Bela Guttmann: Uma lenda do futebol no século vinte. São Paulo: Estação Liberdade.

Couto, J. G. (2004, 30 de outubro). Por quem os sinos dobram. Folha de São Paulo. Recuperado de https://www1.folha.uol.com.br/fsp/esporte/fk3010200427.htm.

Couto, J. G. (2009). Futebol brasileiro hoje. São Paulo: Publifolha.

DaMatta, R. (1979). Carnavais, malandros e heróis: Para uma sociologia do dilema brasileiro. Rio de Janeiro: Zahar.

DaMatta, R. (1982). Esporte na sociedade: Um ensaio sobre o futebol brasileiro. Em Universo do futebol. Rio de Janeiro: Pinakotek.

DaMatta, R. (1994). Antropologia do óbvio. Revista USP, 22, 10-17.

DaMatta, R. (2005). Tocquevilleanas: Notícias da América. Rio de Janeiro: Rocco.

Freyre, G. (2003). Prefácio. Em M. Rodrigues, O Negro no futebol brasileiro (pp. 24-26). Rio de Janeiro: Mauad.

Ginzburg, C. (1989). Mitos, emblemas, sinais. São Paulo: Companhia das Letras.

Giorgetti, U. (Director). (1998). Boleiros: era uma vez o futebol. [Filme]. Brasil.

Gonçalves, M. C., e Vaz, A. F. (2017). Corpo/matéria, gestos/material: Para pensar uma estética dos esportes. Educação, (40), 126-135.

Gumbrecht, H. U. (2007). Elogio da beleza atlética. São Paulo: Companhia das Letras.

Hobsbawm, E. (1983). Mass-producing traditions: Europe, 1870-1914. Em E. Hobsbawm e T. Ranger (orgs.), The invention of tradition. Cambridge: Cambridge University.

Morgan, W. J. (1994). Leftist theories of sport: A critique and reconstruction. Urbana und Chicago: University of Illinois.

Pasolini, P. P. (2005, 6 de março). 0 gol fatal. Folha de São Paulo. Recuperado de https://www1.folha.uol.com.br/fsp/mais/fs0603200506.htm.

Pereira, L. G., e Vaz, A. F. (2012). A “Alegria do povo”: Cinema, esporte, herói. História: Questões \& Debates, 57(2), 175-190.

Prado Júnior, B. (2002, 7 de julho). Alegria: 0 gol do Ronaldinho. Folha de São Paulo, (26.758), p. d5.

Prado, D. A. (1997). Seres, coisas, lugares: Do teatro ao futebol. São Paulo: Companhia das Letras.

Ribeiro, D. (1996, 7 de agosto). Viva elas. Folha de São Paulo, (24596), p. 2.

Rigauer, B. (2000). Marxist theories. Em J. Coakley e E. Dunning (eds.), Handbook of sports studies (28-47). Londres: Sage. 
Rocha, E. (1996). As invenções do cotidiano: O do descobrimento do Brasil e a conquista do tetra. Pesquisa de Campo, (3-4), 9-20.

Rocha, J. C. C. (2006). A guerra de relatos no Brasil contemporâneo: Ou a "dialética da marginalidade". Santa Maria: Letras.

Rodrigues Filho, M. (2003). O negro no futebol brasileiro. (4⿳亠丷a . ed.). Rio de Janeiro: Civilização Brasileira.

Rosenfeld, A. (1993). Negro, macumba e futebol. São Paulo: Perspectiva.

Soares, A. J. G. (1999). História e invenção de tradições no campo do futebol. Estudos Históricos: Esporte e Lazer, 23, 119-147.

Unger, R. M. (2018). Depois do colonialismo mental: Repensar e reorganizar o Brasil. São Paulo: Autonomia Literária.

Vaz, A. F. (2004). Sport und sportkritik im zivilisations- und kulturpozess: Analysen nach Adorno \& Horkheimer, Elias und DaMatta. Frankfurt: Afra.

Vaz, A. F. (2011). Soccer, improvisation, clichés: Brazilianness in dispute. Critical Studies in Improvisation, 7(1).

Vaz, A. F. (2019). Uma Europa inventada pelo futebol. Movimento, 24(4), 1395-1406.

Vaz, A. F. (2021). Sport and society in the writings of Roberto DaMatta. Em S. S. Giglio, e M. W. Proni (eds.). Football and social sciences in Brazil (pp. 133-147.). Cham: Springer.

Welsch, W. (1999). Sport: Ästhetisch betrachtet - Und sogar als Kunst? Em S. Güldenpfennig, e D. Krickow (eds.), Deutsches Olympisches Institut (DOI): Jahrbuch 1998. Sankt Augustin: Academia.

Wisnik, J. M. (2002, 26 de maio). 0 gol de Romário... Folha de São Paulo. Recuperado de https://www1.folha.uol.com.br/fsp/mais/fs2605200206.htm.

Wisnik, J. M. (2008). Veneno remédio: O futebol e o Brasil. São Paulo: Companhia das Letras. 